\title{
Universities, Regional Policy and the Knowledge Economy
}

\author{
MICHAEL A. PETERS \\ University of Glasgow, United Kingdom \\ TIM MAY \\ University of Salford, United Kingdom
}

\begin{abstract}
This article focuses on the spatial clustering dimension of new information and communications technology (ICT)-driven economic activity based on knowledge industries and especially the tacit knowledge synergies to be achieved through networking in geographical space. The article first details the new knowledge economy, reviewing claims made for its distinctiveness and its role in raising levels of productivity before turning to a brief study of the clustering effects of new ICT-driven economic activity and the development of policies designed to enhance regional development. The remainder of the article details a case study - Univercities: the Manchester Knowledge Capital Initiative in the North-west of the United Kingdom based on recent research into the attempt to create a 'Knowledge Capital' within the Greater Manchester conurbation, which is designed to position Manchester at the heart of the knowledge economy.
\end{abstract}

\section{Introduction: the new economy?}

In the West educational policy has given way to talk of the knowledge economy under the sway of world policy organisations like the Organisation for Economic Co-operation and Development (OECD) and the World Bank. The terms 'knowledge economy' and 'knowledge capitalism' emerged in the mid-1990s to become national policy templates for many Western governments and developing economies. The United Kingdom (UK) Government, for example, has pronounced the end of the comprehensive school, based on a 'one-size-fits-all' welfare-state ideology, and signalled a shift to a fully consumer-driven system of public services in health and education, 
based on the market ideology of choice and diversity. This shift to the 'social market' is underwritten and accompanied by an emphasis on national competitiveness within the global economy and the way in which the 'new economy' demands new levels of flexible skilled knowledge workers. This chapter examines the discourse of the knowledge economy and education as an 'industry of the future' that can promote regional development, with the attendant emphasis on public-private partnerships and the cultural reconstruction of city entrepreneurial cultures and clustering of knowledge capital activities.

Digitalisation, speed and compression are the forces at work that have transformed the global economy and now have begun to affect every aspect of knowledge production - its organisation, storage, retrieval, and transmission. The knowledge economy has certainly arrived, although this does not mean the end of the business cycle, as many early advocates of the new economy maintained. But it does signal structural economic shifts and new sources of growth in some Western economies (e.g. USA, Finland) that delivered both low unemployment and low inflation due to increased productivity. While it is clear that investment in ICT (information and communications technology) and ICT-driven productivity growth has led to a higher growth path, there is a risk of exaggerating the growth potential due to ICT investment alone. Yet as a recent OECD report The New Economy: beyond the hype (2001) put it:

It would be wrong to conclude that there was nothing exceptional about the recent US experience, that the new economy was in fact a myth. Some of the arguments posited by new economy sceptics are of course true: the effect of ICT may be no greater than other important inventions of the past, like electricity generation and the internal combustion engine.

Moreover, far greater productivity surges were recorded in previous decades, not least in the period before the 1970s.

(http: / / www.oecd.org/dataoecd/2/262380634.pdf)

Nevertheless, the evidence suggests that something new is taking place in the structure of OECD economies (p. 10). The report continues by maintaining that ICT has facilitated

productivity enhancing changes in the firm, in both new and traditional industries, but only when accompanied with greater skills and changes in the organisation of work. Consequently, policies that engage ICT, human capital, innovation and entrepreneurship in the growth process, alongside fundamental policies to control inflation and instil competition, while controlling public finances are likely to bear the most fruit over the longer term. (p. 10)

Crucially, the report investigates and recommends a set of relationships and policies that harness ICT, human capital, innovation and business creation, focusing on the wider diffusion of ICT and the role of education and training policies in meeting today's skill requirements. 
Clearly, the Internet economy is becoming an integral part of the global economy, creating jobs, increasing productivity and transforming companies and institutions. Employment in the Internet economy is growing faster than in the traditional economy. In the US economy alone the Internet generated an estimated $\$ 830$ billion in revenues in 2000, which represented a $58 \%$ increase over 1989.[1] J. Bradford De Long, former Deputy Assistant Secretary for Economic Policy in the US Department of the Treasury, depicts the new economy', asserting it is both a knowledge and an innovation knowledge where clusters of innovation, based on new technologies and new business models, succeed each other. He maintains it is likely to continue for an extended time and its consequences are pervasive. He provides an analytical overview of the digital economy which conveys how different it is from the market economy of orthodox economics. He likens the digital economy to the enclosure of the common lands in early modern Britain, which paved the way for the agricultural and industrial revolutions. Digital commodities, he maintains, do not behave like standard goods and services of economic theory: they are non-rivalrous, barely excludable and not transparent. The store of music tracks is not diminished when one downloads a track from the Internet; it is difficult, if not impossible, to restrict distribution of goods that can be reproduced with no or little cost, and; a consumer does not know how good software is before purchase or indeed how its successor versions will perform in the future.

It is important to recognise that the knowledge economy is both classical and new. Danny Quah of the London School of Economics indicates that the economic importance of knowledge can be found in examples where deployment of machines boosted economic performance such as in the Industrial Revolution. By contrast, he talks of the 'weightless economy', 'where the economic significance of knowledge achieves its greatest contemporary resonance' and suggests it comprises four main elements:

1. Information and communications technology (ICT), the Internet.

2. Intellectual assets: Not only patents and copyrights but also, more

broadly, name brands, trademarks, advertising, financial and consulting services, and education.

3. Electronic libraries and databases: including new media, video entertainment, and broadcasting.

4. Biotechnology: carbon-based libraries and databases, pharmaceuticals. (http:/ / econ.lse.ac.uk/staff/dquah/tweirlo.html)

Elsewhere he argues:

Digital goods are bitstrings, sequences of 0 s and $1 \mathrm{~s}$, that have economic value. They are distinguished from other goods by five characteristics: digital goods are nonrival, infinitely expansible, discrete, aspatial, and recombinant. (Quah, 2003, http:/ / econ.lse.ac.uk/staff/dquah/dp0212hbne.html) 
Quah (2001) also has been influential in suggesting that knowledge concentrations spontaneously emerge in space, even when physical distance and transportation costs are irrelevant. The dynamics of spatial distributions manifest themselves in convergent clusters. This is an important feature, especially given the development of the e-conomy first in Silicon Valley.

In Getting the Measure of the New Economy, Diane Coyle and Danny Quah (2002), while noting the $11 \%$ productivity gap between the UK and Germany, and the $45 \%$ productivity gap with the USA (1999 base year), at the same time acknowledge the considerable impact of ICT on the economy. They demonstrate on the basis of evidence from the USA that those businesses responding the quickest to ICT developments are driving forward the rest of the economy. At the same time they maintain that technology takes time to filter through and set up the cascade effects that are evident in change organisational and business practices. They acknowledge that after the dot-com bubble burst, confidence in the new economy has waned yet they remain optimistic about long-term, technology-led economic growth based on the processing power of the microchip, which encompasses well-known developments like the Internet and developments in information and communications technologies with gene technology, nanotechnology, robotics and advanced materials. They write:

Advocates of the notion of the new economy cited supporting factors uniquely combined in the US economy, particularly minimal government, high levels of competition, encouragement of entrepreneurship, and access to venture capital. What gave the theory bite, though, was the vision that the widespread diffusion of technology had permanently changed the way economies had worked for the better. (Coyle \& Quah, 2002, http:/ / www.theworkfoundation.com/pdf/1843730014.pdf)

They also develop a set of indicators to measure the changes to the deep structure of the economy brought about by technology.

\section{Clustering Effects of New ICT-driven Economic Activity}

One of the most significant features of these economic changes is the way in which against expectations a sort of geographical clustering of new economic activity appears to have taken place. This clustering even applies to the broader accounts of its development and spread. The Silicon Valley view of the economy maintains that the centre-periphery model, with development spreading from the West Coast, south of Palo Alto, forced the development of a single international market that is dominated by American multinationals. By contrast, the pluri-view suggests that Internet leading-edge use and ecommerce centres are beginning to emerge in Europe and Asia, and as new technologies emerge, along with different uses, business models and legal frameworks, they will challenge the early dominance of American policy and the international market. If there are different local configurations of market 
demand and distinct trajectories of development and separate national economies, then they are most likely to emerge around fundamental empirical criteria such as distinct technologies and applications; locally differentiated market structures; different business models; perhaps, distinct structures of comparative advantage; and, culturally different legal and policy frameworks.

The alleged aspatial character of digital goods seems to fly in the face of empirical evidence. Given their 'weightlessness', digital goods are theorised to spread easily across the globe without favouring particular locations, yet empirical analysis reveals exactly the opposite - that the production of digital goods like other goods becomes geographically concentrated. In fact, as Quah (2002, p. 38) argues, 'the geographical clustering of computer software and digital media production, academic and commercial R\&D, and financial services, among other digital goods, is likely tighter than for ordinary goods and services'. He argues further that the aspatiality of digital goods does not imply that space no longer matters; indeed, only transportation costs no longer matter, others factors normally associated with geography taking on a heightened importance. He indicates that embodied human capital clusters geographically because communication of tacit knowledge is most efficient in close proximity. In other words, 'synchronous face-to-face interactions matter for transmitting (nonbitstring) knowledge' (Quah, 2002, p. 39). On this understanding sometimes learning is considered the core of a theory of clustering, focusing on the existence, the internal organisation and boundaries of the cluster (Maskell, 2001).

The major theoretical question is why has industry clustering reappeared in advanced economies when it had all but disappeared in the mid-twentieth century. Phillip Cooke (2002) suggests that the knowledge economy consists in fragments and runs against conventional economic analysis that assumes individualistic competition within an ordered economic equilibrium. By contrast, with the knowledge economy he points to disequilibrium or economic and social imbalance, collaborative economic action as the basis of modern capitalism, and the systemic nature of strategic competitiveness of groups' actions based on consensus rather than individual opportunism (Cooke, 2002, p. 1). Against the status of the lonely Nietzschean heroic individual and entrepreneur characterised by Schumpeter, Cook suggests the sources of innovation lie in networks of social relationships, that is, knowledge networks. He argues:

clusters are crucial to economic imbalance, ... they rest upon collaboration

of a generally non-market-destroying type that is simply essential for modern economic organization, and ... clusters have systemic organizational characteristics that go against much economic orthodoxy. (Cook, 2002, p. 2)

Such an analysis then directly leads to an emphasis on 'the geographical dimension of learning, knowledge transfer, collaboration and the exploitation of the spillovers' (p. 2). Cook concurs with Quah that 'proximity in a cluster 
offers the opportunity for tacit knowledge exchange or "treacherous" learning that may be hindered in large firms by "group think" and corporate culture" (p. 3).

Government policy has changed to accent and foster the geographical cluster of new economic activity. It is clear that that Labour Government sees the 'knowledge-driven economy' as key to the UK's competitive success. The strategy behind the adoption of this concept is to promote high-tech venture capital 'clusters' in the regions. In part the UK strategy is strongly influenced by Michael Porter's (1998) work on the role of clusters in forging US innovativeness and competitiveness. The regional development agencies (RDAs) in the UK are encouraged to develop 'cluster' policies based on knowledge industries. For instance, the White Paper on Enterprise, Skills and Innovation (Department of Trade and Industry, 2001) emphasises the role of universities in the regional development of clusters in the knowledge economy:

The role of our universities in the economy is crucial. They are powerful drivers of innovation and change in science and technology, the arts, humanities, design and other creative disciplines. They produce people with knowledge and skills; they generate new knowledge and import it from diverse sources; and they apply knowledge in a range of environments. They are also the seedbed for new industries, products and services and are at the hub of business networks and industrial clusters of the knowledge economy.

The examples can be developed further. The UK Office of Science and Technology (OST) emphasises the importance of 'knowledge transfer':

Within a modern, knowledge driven economy, knowledge transfer is about transferring good ideas, research results and skills between universities, other research organisations, business and the wider community to enable innovative new products and services to be developed. (http:/ / www.ost.gov.uk/enterprise/knowledge/index.htm)

This kind of emphasis can be clearly seen in OST's Higher Education Innovation Fund (HEIF):

We have now established the Higher Education Innovation Fund (HEIF), which together with the existing Higher Education Reach Out to Business and the Community fund (HEROBC), is worth $£ 140$ million over three years, to further build on universities' potential to act as drivers of growth in the knowledge economy. HEIF provides special funding to enable HEIs to respond to the needs of business, through both the continuing development of capacity in universities to interact with business and the community (building on HEROBC), and large, strategic, collaborative projects to strengthen university-business partnerships. (http:/ / www.ost.gov.uk/enterprise/knowledge/index.htm)

More broadly, the UK Government's economic strategy can be seen as being based on investment in science, engineering and technology. In the recent 
White Paper Investing in Innovation: a strategy for science, engineering and technology (OST, 2002) the focus is on the twin strategies of renewing the physical and human capital which underpins research and investing in capacity to exploit the burgeoning opportunities of new science. In this strategy universities are encouraged to link with business to create value for the regional and national economy where RDAs play an enhanced role in developing knowledge transfer programmes.

The regional development role of knowledge industries has received increasing attention in the USA and by the European Union (EU). CEOs for Cities, for example, an organisation that explores best practices in urban economic development and proposes new strategic frameworks on emerging trends, recently partnered with the Initiative for a Competitive Inner City to develop a national study of the impact of higher education on urban economies. The study introduces a strategic impact framework and features case studies and best practices in university partnerships, including studies of both Virginia Commonwealth University in Richmond and Columbia University in New York City. The report begins:

\begin{abstract}
Unleashing the local economic development capacity of these institutions (colleges and universities) should be a national priority. While ambitious, it is an agenda that does not require massive new funding or heroic changes in day-to-day operations of colleges and universities, city government or community groups. (Joint Study by Initiative for a Competitive Inner City and CEOs for Cities, 2002, p. 2)
\end{abstract}

The Lisbon European Council set the 'bold and ambitious' 10-year goal of making the EU the most dynamic, competitive, sustainable, knowledge-based economy in the world. Yet the transition to the knowledge-based economy has been slow and there is now recognition that spending on higher education needs to be strengthened. The argument is made that the European ability to produce, diffuse and use knowledge effectively relies heavily on its capacity to produce highly educated people for its firms to be engaged in a continuing process of innovation. Yet lifelong learning is still not a reality for most European citizens. It is now recognised that the European innovation systems have not been successful in exploiting the new techno-economic paradigm rooted in information technology that is reflected in the European paradox of a strong science base but weak innovation performance. As Lundvall \& Borras (1998) argue: 'A major policy objective of innovation policy must be to contribute to the learning capability of firms, knowledge institutions and people and to promote innovation and adaptation'. They point to 'human resource development, new forms of firm organisation, network formation, new roles for knowledge intensive business services and for universities as the key elements in speeding up the catching-up within this paradigm'. A new regional policy focusing increasingly on the role of universities and of higher education more generally, first recognised in the Bologna agreement, has begun to theorise these economic imperatives in new spatialised knowledge 
networks. The role of universities in regional development has gone beyond the study of technology transfer and direct employment effects of spin-off companies and the establishment of science parks, to embrace the wider ethos of the enhancement of human and social capital within a region, including emphasis on student recruitment and regional placement policies, university professional development programmes for local managers based on local research, the development of research networks that serve as a basis for embedding the local businesses in the global economy, and a more research and information-sensitive negotiation of the local/global interface.

\section{Univercities: the Manchester Knowledge Capital Initiative}

In the North-west of the UK, this policy context is reflected in several recent developments. The North West Universities Association was formed in 1999 and works increasingly closely with the Northwest Development Agency (NWDA) and other regional partners. In 2001, the North-west established England's first science council, bringing together representatives from industry, regional agencies and the universities to lobby on behalf of the region and advise and launch the Regional Science Strategy (NWDA, 2002). This was subsequently published in 2002 and sets forward cluster-based actions in five priority areas (biotechnology, environmental technologies, chemicals, aerospace and nuclear energy) to link universities better with industry and regional partners. The model is one of 'excellence with relevance'.

Many regional development agencies are now devolving the implementation of aspects of regional strategies to sub-regional bodies, recognising that some issues are better tackled at a lower spatial scale. At the same time, local authorities are collaborating with neighbours and partners to 'upscale' their cities and tackle joint issues through a cross-boundary approach. The movement also now includes health authorities, universities, local education authorities, skills agencies, charities and the police who are active in their own city-regional partnerships. In a number of cases the private sector is giving the lead to city-regional thinking, particularly in the arena of economic and planning policy (Centre for Sustainable Urban and Regional Futures, 2003). In the Greater Manchester context, we see the development of the Greater Manchester sub-regional strategy, led by the Association of Greater Manchester Authorities (AGMA), launched on 20 June 2003. An essential element of this strategy focuses on enhancing the sub-regional core and building on the university assets concentrated therein (AGMA, 2002, p. 16).

With this background in mind the vision of 'Manchester: Knowledge Capital' (KC) is:

to create an internationally acclaimed 'Knowledge Capital' within the Greater Manchester conurbation, which will position Manchester, branded as the Knowledge Capital, at the heart of the Knowledge Economy, significantly contributing to the economic growth of the nation and the North West region leading to a healthier city/region with a vibrant, safe 
and attractive environment in which to live, work and play, for people of all ages, social and cultural backgrounds.

(http:// www.manchesterknowledge.com/knowledge.html)

This initiative can be seen in the context of two major changes which are fundamentally reshaping our society, economy and the institutions and practices of modern life: the development of the knowledge economy and changing notions of scale. These two factors have led to increasing attention being given to the role of universities in driving local and regional economies, reflected in a wealth of new policies being developed at international, national, regional and sub-regional scales. These policies raise many challenges for universities and for their localities and a number of different responses, as international and national comparisons indicate. In this context, $\mathrm{KC}$ represents a much needed and valuable opportunity for the universities to position themselves at the heart of the city-region's response to the global knowledge economy.

From the 40 interviews and documentary work conducted in the four universities (University of Manchester, Manchester Metropolitan University [MMU], University of Salford and UMIST) with senior managers and those individuals who were considered key to successful implementation of KC, we can see the extent to which understandings remain aspirational at a variety of levels across the universities. Relatively speaking, the most well-developed attempts at clarification of the meaning of $\mathrm{KC}$ are provided, not surprisingly, by those who are championing and driving the process for the universities. Overall, these are a small number of individuals in senior management positions. Here we see an explicit identification of a role; that is, creating the conditions that will enable its development. The role of senior managers is to create not only a vision, but also an infrastructure that will function without too much top-down planning to provide support and incentives.

Yet a clear aim of $\mathrm{KC}$ and one given by central government is that the universities should act in collaboration with each other and with other agencies for the benefit of the city-region. This was both implicit and explicit in many of the interviews. In particular, one senior manager spoke of a great strength of the city of Manchester being a 'mutual trust between the key players'. This is matched with the view of one senior manager in Manchester City Council who said that KC provided a context in which: 'we construct the new HEI sector in such a way that it interfaces very effectively and coherently with a significantly wider world [than has been historically the case]'. Many of these interviewees whilst unpacking, or alternatively trying hard to populate, the notion of $\mathrm{KC}$ also sought clarification as to its geographical focus. Some took it to concentrate on the North-west of England, others Greater Manchester, some Manchester, but all with a degree of uncertainty. The idea of 'capital' itself was also a source of ambiguity, with ideas of human capital and innovation mixing with those of cultural and physical capital, and Manchester seeking to place itself more securely as the 'capital' of the North-west. Importantly, what we see here are differences in aspiration and interpretation according to the remit of 
the individual interviewed. Those further up the hierarchy tended to be supportive of the idea in terms of its potential, whilst those with a concern for implementation and its implications for practice tended to be more uncertain. This belief came from an experience of so many 'next big thing' initiatives that produced more work without tangible benefit. It also came from the institutional incentives that were available for engagement at different levels. As one interviewee put it in relation to practices surrounding international research excellence (of which they were a part), KC should be about:

achieving some sort of culture shift within the institution ... the notion that you can only be taken seriously if you go to conferences in North America or Munich or whatever and that anything where you dirty your hands on things local, I mean, by definition is seen as trivial ... the international and the local can readily co-exist together ... [the University needs] levers to pull locally and to ensure that this might happen and all of the incentives and reward structures still tend to reinforce the argument.

Incentivisation and reward within the different institutions and how they relate to practice is clearly a major issue and one that has not been adequately considered in relation to the developmental potential of $\mathrm{KC}$.

Two issues, in particular, then become of importance. First, to develop the conditions that facilitate activities and second, for those activities to feed into $\mathrm{KC}$ in order that it moves from concept to action. What is required for this process is a set of practices that would populate the concept. As one person put it, it cannot just be about:

museums and office blocks and such like in the centre, but actually focus on regeneration through knowledge applied to entrepreneurial activities ... that seems to me to be an excellent extension and the next stage after we've physically transformed the city into something worth living in ... then we've got to jump start some entrepreneurial activity or it will be another Sheffield Centre for Popular Culture!

There were also differences between the institutions in terms of how they approach the potential of knowledge capital. Thus, those associated with UMIST/Victoria tended to see the development of $\mathrm{KC}$ as one of 'added value'. In other words, it was concerned with repackaging and exploiting existing opportunities for institutional benefit and that of the city as a whole, in terms of the location of the University and its relations with key stakeholders. This concerned the development of relations of mutuality with the City Council and other organisations in providing a context and environment for attracting staff, finance, investment and facilities to Manchester. It would also provide further evidence of an 'innovative milieu' through the development of incubation facilities (for the exploitation of knowledge), infrastructure (physical and human) and other visible signs of activity: for example, cultural in relation to art galleries, theatres and museums. To this extent the development of $\mathrm{KC}$ is part of the overall strategy of the 'Project Unity' merger in seeking to 
counterbalance the 'Golden Triangle' of Oxford, Cambridge and London and become a 'Harvard of the North' and part of an extended 'Golden Diamond'.

Such international aspirations should be seen against a change in recent years in which both institutions have moved a long way from being seen as 'in' but not 'of the region. It was emphasised that the shift towards an internationally focused and renowned institution was not incompatible with a local and engaged focus as it was a contributor to the 'well-being' of an area. The development of Victoria as a world-class research university was illustrated by developments in bio-medical research (a $£ 40$ million complex for bio-medical research relates to what was described as a 'bio-medical corridor' in Oxford Road) and growing relationships between medical facilities, the National Health Service, pharmaceutical companies and spin-out enterprises. Victoria's focus was in positioning itself as an international, first-class, sciencebased, research university able to attract the brightest students and leadingedge academics and develop the facilities that match these aspirations to particular developments. The associations that exist between academics within Greater Manchester and the North-west region temper the international dimension of activities in some departments: for example, bio-medical science and collaborative links with Liverpool. In addition, the level of activity may not directly relate to the locality, but that is not to suggest it does not have local implications. For instance, in terms of the opportunities presented by the merger for new centres of research excellence, this person spoke about a centre for climate change:

the atmospheric physicists know all about modelling of the climate and atmosphere etc, making connections with the earth sciences, setting up a more environmentally orientated physics and earth sciences school ... the merger is an opportunity to reconfigure into these new knowledge lumps ... so in that sense there's tremendous opportunity for rearranging some of the intellectual furniture, and I would have thought that presents opportunities for new research directions focused on spin off and entrepreneurial activities.

Allowing such possibilities to flourish over time, as opposed to imposing a vision upon sets of practices, is precisely how some of the most advantageous developments may take place. In addition, whilst there are international aspirations, there are also different levels of engagement within Victoria and UMIST. The departments of Planning and Landscape, and Architecture, for example, have worked on KC design projects and possess a long tradition of working with local communities in terms of outreach, widening participation and issues associated with multiculturalism.

$\mathrm{KC}$ at MMU tended not to be seen as a repackaging of existing processes, but as a means of continually cultivating relationships between the University and the region around a number of strategic themes in which they were investing their energies and resources. These areas of activity were: Network for Enterprise; Innovation in Art and Design; Regeneration; Sport and Physical 
Activity; Clothing, Design and Technology and Aviation, Transport and Environment.

KC was regarded as enhancing those areas of activity, as well as being transformative; in the process it brought greater recognition to the University in terms of its overall identity. This has been prevalent in terms of creativity and culture, for example, art, design, fashion and sport. MMU was regarded as having a strong vocational base with a regional focus. The University possessed clear areas of research excellence (seven four-star departments and one five-star department in the latest Research Assessment Exercise), but was seen as having a focus on widening participation through outreach activities, through enterprise in local schools, through the large number of teachers who are trained in the institution, continuing professional development and via such initiatives as the Community Entrepreneurship Scheme. Problem solving and innovation with local businesses led in interviews to an emphasis upon practical engagement. For example, in terms of fashion, MMU deals with developments and ideas for clothes which retail rather than high fashion. Thinking about this emphasis in terms of seeking to welcome people into universities who would not otherwise come in, this person noted in respect to the Manchester Fashion Network that there was an opportunity to enhance recognition through KC. Overall, it was viewed as an important means of providing coordination and coherence to a wide variety of activities that saw the University seeking to reach out to people who would not normally engage with higher education.

This latter aspiration is shared with Salford, in which one senior manager viewed $\mathrm{KC}$ as an 'infrastructure of possibilities'. Here academics and the institutions could form relationships of knowledge creation, production and sharing for multiple beneficiaries. KC was an aspiration to create a structure within which people can move and be creative. There was also the sense generally that $\mathrm{KC}$ related to aspirations in terms of the mixed aims at Salford of teaching, research and enterprise. The flow of knowledge and the movement of people within a defined area was key to this notion.

Salford was seen to have notable pockets of research excellence: for example, in Information Systems, the Built Environment, European Studies and Urban Regeneration, Media, Art and Design, Public Health, as well training in relation to Professions Allied to Medicine. Its reputation in these areas was seen in terms of its distinctive strengths in addressing business, industrial and commercial interests in, for example, the design and deployment of 'enabling technologies' through working in partnership. This ethos was linked to the potential seen in KC. An emphasis was also placed on widening access and participation via a number of initiatives, with the aim of raising young people's aspirations. Mentoring was, for example, one programme of work mentioned, whilst the relationship between skills and student was seen to be accommodated within Salford. Overall, therefore, KC was seen as enhancing existing agendas in teaching, enterprise and research, all of which 
were driven by the idea of being an 'engaged' university working in partnership with a variety of stakeholders.

All this takes place against a background of change in which understanding differences between institutions, as well as similarities, is required. At the launch of the Higher Education Funding Council for England's draft strategic plan (2003-08), Sir Howard Newby was quoted as saying that individual universities: 'must build upon their own chosen areas of strength, and work in collaboration with other providers, so that the sector as a whole continues to deliver all that is required of it in the increasingly competitive global marketplace'.

Complementarity, on the basis of an understanding of distinctiveness, was seen as crucial to the development of KC by all those interviewed. This is not to suggest that there is not competition between the universities as they seek to differentiate their niche markets and convey a particular identity to an outside audience. That means recognising the distinctive strengths of each institution.

In terms of further engagement and making the universities meaningful to citizens, a large number of deprived wards surround Manchester. As one person put it: 'we have a huge mountain to climb in terms of raising the aspirations of local people ... young people'. Spatially speaking, this also relates to a tension between what is seen as the 'urban core'. KC might be very successful, for example, in attracting a larger pool of knowledge workers. Some of these may stay in the 'centre', but there are no schools and so where will they go if they have, or want, children? In this sense, how will this community benefit those who already exist in areas such as East Manchester, Hulme and Moss Side? How are these latter groups to benefit from KC?

New urban and regional education futures have recently become the basis for both the knowledge economy and also dreams of the renewal of the post-industrial city. This movement that depends upon a reconceptualisation of regional development has the prospect of emphasising the university as a local source of research, expertise and innovation and providing a knowledge base for local industries to thrive in the global economy. Perhaps, more importantly, it holds the promise of rearticulating the links between the university and the communities it serves to enhance civic traditions and thickening democracy.

\section{Notes}

[1] See The Internet Economy Indicators at www.internetindicators.com/ execsummry.html

\section{References}

Association of Greater Manchester Authorities (AGMA) (2002) Draft Greater Manchester Strategy. Wigan: AGMA. 
Centre for Sustainable Urban and Regional Futures (SURF) (2003) Evaluating Urban Futures: enhancing quality and improving effectiveness. SURF, University of Salford. Available at: www.surf.salford.ac.uk

Cooke, P. (2002) Knowledge Economies: clusters, learning and cooperative advantage. London: Routledge.

Coyle, D. \& Quah, D. (2002) Getting the Measure of the New Economy. Available at: http:/ / www.theworkfoundation.com/pdf/ 1843730014.pdf

Department of Trade and Industry (2001) Opportunity for All in a World of Change: a White Paper on enterprise, skills and innovation. Available at: www.dti.gov.uk/ opportunityforall/

Joint Study by Initiative for a Competitive Inner City and CEOs for Cities (2002) Leveraging Colleges and Universities for Urban Economic Revitalization: an action agenda. Available at: www.ceosforcities.org/research/2002/leveraging_colleges/

Lundvall, B.-A. \& Borras, S. (1998) Innovation Policy in the Globalising Learning Economy. Available at: http://www.cordis.lu/tser/src/sumfinal.htm

Maskell, P. (2001) Growth and Territorial Configuration of Economic Activity. Available at: www.druid.dk/conferences/nw/paper1/maskell.pdf

Northwest Development Agency (NWDA) (2002) Science Strategy England's Northwest. Warrington: NWDA.

Office of Science and Technology (OST) 'Knowledge Transfer', 'Exploitation Funding' webpage. Available at: www.ost.gov.uk/enterprise/knowledge/index.htm

Office of Science and Technology (OST) (2002) Investing in Innovation: a strategy for science, engineering and technology. Available at: www.ost.gov.uk/policy/ science_strategy.pdf

Porter, M. (2000) Location, Competition and Economic Development: local clusters in a global economy, Economic Development Quarterly, 14(1), pp. 15-34.

Quah, D. (2001) Demand-driven Knowledge Cluster in a Weightless Economy. Available at: http:/ / econ.lse.ac.uk/dquah/p/0104dkc.pdf

Quah, D. (2002) Digital Goods and the New Economy. Centre for Economic Performance, London School of Economics. Available at: http://cep.lse.ac.uk/pubs/download/ dp0563.pdf

Quah, D. (2003) Digital Goods and the New Economy, in D.C. Jones (Ed.) New Economy Handbook. New York: Academic Press.

MICHAEL PETERS is Research Professor of Education at the University of Glasgow, United Kingdom and holds posts as Adjunct Professor of Education at the University of Auckland and Adjunct Professor of Communication Studies at the Auckland University of Technology, New Zealand. He is Co-Director of the (online) Doctoral Programme in Education at the University of Glasgow. He is executive editor of Educational Philosophy and Theory (Blackwell) and coeditor of two international online-only journals, Policy Futures in Education and E-Learning (Symposium Journals). He has research interests in educational theory and policy, and in contemporary philosophy. He has published over twenty-five books and edited collections in these fields, including: 
Poststructuralism and Educational Research (with Nick Burbules) (2004); Futures of Critical Theory (2003); Poststructuralism, Marxism and Neoliberalism: between theory and politics (2001); Nietzsche's Legacy for Education: past and present values (2001); and Wittgenstein: philosophy, postmodernism, pedagogy (1999) with James Marshall.

Correspondence: Professor Michael A. Peters, Department of Educational Studies, University of Glasgow, St Andrews Building, 11 Eldon Street, Glasgow G3 6NH, United Kingdom (m.peters@educ.gla.ac.uk).

TIM MAY is Lead Director of the Centre for Sustainable Urban and Regional Futures, University of Salford, and with colleagues, conducts research into urban futures, science policy and knowledge and regionalization. He has authored and edited books on social theory, methodology, methods and philosophy of social science and organisational transformation and is series editor of Issues in Society (McGraw-Hill/ Open University Press).

Correspondence: Tim May, Centre for Sustainable Urban and Regional Futures, 113-115 Portland Street, Manchester M1 6DW, United Kingdom (t.may@salford.ac.uk). 